\title{
Sperm storage in Hemidactylus mabouia: Morphological and ultrastructural aspects of a reproductive strategy
}

\author{
Katiane de Oliveira Pinto Coelho Nogueira ${ }^{a, *}$, Sirlene Souza Rodrigues Sartori ${ }^{\mathrm{b}}$, \\ Vinícius Albano Araújo ${ }^{\mathrm{b}}$, Clóvis Andrade Neves ${ }^{\mathrm{b}}$, Benjamin Kolisnyk ${ }^{\mathrm{c}}$ \\ a Universidade Federal de Ouro Preto, Brazil \\ b Universidade Federal de Viçosa, Brazil \\ ${ }^{c}$ Robarts Research Institute, The University of Western Ontario, Canada
}

\section{A R T I C L E I N F O}

\section{Article history:}

Received 10 July 2014

Received in revised form 19 June 2015

Accepted 25 June 2015

Available online 27 June 2015

\section{Keywords:}

Spermatozoa

Sperm storage

Lizard

Uterine tube

Reproductive strategy

Reptile

\begin{abstract}
A B S T R A C T
Sperm storage is a common phenomenon in most female reptiles. Evidence of sperm storage is based on the observation that female fertilization occurs even when females are separated from males, as well as the presence of agglomerates of spermatozoa in specific regions of the oviducts. Lizards are capable of storing sperm in the uterine tube, vagina, or in both regions. However, representatives of the Gekkonidae family commonly store spermatozoa in the uterine tube, which is considered an ancestral character state for Squamates. Using comparative techniques of light, transmission and scanning electron microscopy, we observed stored sperm organized in compact bundles with their heads facing the bottom of the crypts of the uterine tube, indicating chemotactic attraction. The alignment and packing of spermatozoa in Hemidactylus mabouia indicates that the process of evacuation of the crypts for fertilization may be related to the passage of the egg that exerts mechanical pressure against the walls of the uterine tube, causing its distension and the release of spermatozoa. We conclude that the sperm storage region and the morphological organization of the crypts in the uterine tube of $H$. mabouia is similar to other previously studied species of lizards, supporting the notion that sperm storage is a common reproductive strategy among female reptiles.
\end{abstract}

(c) 2015 Elsevier B.V. All rights reserved.

\section{Introduction}

Sperm storage in the oviduct during the reproductive cycle is a common phenomenon amongst female reptiles, where insemination and ovulation/fertilization occur in distinct periods (Schuett, 1992; Sever and Hamlett, 2002). In 1943, Ludwig and Hahn described sperm storage in

\footnotetext{
* Corresponding author at: Universidade Federal de Ouro Preto, Campus Morro do Cruzeiro, Instituto de Ciências Exatas e Biológicas (ICEB), Departamento de Ciências Biológicas - DECBI, CEP 35400-000/Ouro Preto, MG, Brazil. Tel.: +55 3135591215 .

E-mail addresses: katiane@nupeb.ufop.br, kaolli@yahoo.com.br (K.d.O.P.C. Nogueira).
}

the oviducts of Crotalus viridis viridis females. Saint Girons (1962) and Fox (1963) reported the first studies of such sperm storage in lizards in the 1960s.

Evidence for sperm storage is based on the observation that female fertilization occurs even when the females are separated from males and is related to the presence of agglomerates of spermatozoa in specific regions of the oviducts (Adams and Cooper, 1988). However, the existence of these spermatozoa agglomerates does not guarantee sperm storage. Phagocytosis sites are observed in the reptilian oviduct where a large amount of spermatozoa could be present. Additionally, phagocytosis occurs within the storage sites themselves in lizards (Sever and Hopkins, 2004; Siegel and Server, 2007; Nogueira et al., 
2011a,b). Several spermatozoa have been observed in the vagina of Eumeces egregius lizards (Schafer and Roeding, 1973); however, these findings do not indicate this region as a storage site due to the absence of structures specialized for this function, such as crypts. Similarly, in Hemidactylus mabouia, intense phagocytosis of spermatozoa by vaginal epithelial cells has been observed, despite the fact that no structures specialized in storage were observed; thus, this oviduct region is characterized as an exclusively phagocytic site (Nogueira et al., 2011a,b).

Lizards store spermatozoa in the uterine tube, vagina or both of these regions (Sever and Hopkins, 2004; Siegel and Server, 2007). Conversely, members of the Gekkonidae family generally store sperm in the uterine tube (Cuellar, 1966; Murphy-Walker and Haley, 1996; Girling et al., 1997), and this feature is considered to be the ancestral state for Squamates according to the hypothesis of phylogeny based on spermatozoa storage tubules proposed by Sever and Hamlett in 2002.

Various studies have described and compared the structural and ultrastructural aspects of storage sites in lizards (Cuellar, 1966; Conner and Crews, 1980; Bou-Resli et al., 1981; Girling et al., 1997, 1998; Sever and Hamlett, 2002; Sever and Hopkins, 2004). Here, we describe for the first time the uterine tube sperm storage process in $H$. mabouia, thus providing new insights into the understanding of this important reproductive strategy in a member of the Squamata.

\section{Materials and methods}

\subsection{Animals}

Ten female $H$. mabouia lizards measuring from 52.9 to $59.3 \mathrm{~mm}$ were collected under license number 10504-1 of Instituto Brasileiro do Meio Ambiente e dos Recursos Naturais Renováveis (IBAMA). The carcasses were fixed in a buffered formalin solution (Carson et al., 1973) for $24 \mathrm{~h}$ at room temperature and deposited at the João Moojen Animal Science Museum of the Universidade Federal de Viçosa (UFV), Minas Gerais, Brazil. The experiment was conducted in accordance with the ethical principles for the utilization of laboratory animals published in the Colégio Brasileiro de Experimentação Animal (COBEA). Identification and collection of the reproductive organs was performed in situ via a median longitudinal incision in the ventral region of the animals. The collected material was deposited in vials containing saline solution.

\subsection{Optical microscopy}

Uterine tube fragments were fixed in a buffered formalin solution (Carson et al., 1973) for $24 \mathrm{~h}$ at room temperature and dehydrated in increasing concentrations of ethanol. The fragments were embedded in glycol methacrylate (Historesin ${ }^{\circledR}$, Leica) and sectioned at $2 \mu \mathrm{m}$ in an automatic microtome (Reichert-Jung, Germany). The obtained sections were stained with $1 \%$ toluidine blue/sodium borate and mounted on slides with Entellan ${ }^{\circledR}$ (Merck) for analysis with an Olympus BX-60 microscope.

\subsection{Transmission electron microscopy}

Uterine tube fragments (approximately $1 \mathrm{~mm}^{2}$ ) were fixed in Karnovsky's solution (Sheehan and Hrapchak, 1980 ) for $4 \mathrm{~h}$. The material was then washed with $0.1 \mathrm{M}$ sodium cacodylate buffer ( $\mathrm{pH} 7.2$ ) and post-fixed in $1 \%$ osmium tetroxide for $2 \mathrm{~h}$. The material was subsequently dehydrated in increasing concentrations of acetone and embedded in Epon resin. Ultrathin sections were obtained in an ultramicrotome and contrast stained with $2 \%$ uranyl acetate and $0.2 \%$ lead citrate. The material was examined and photographed using an EM 109-Zeiss transmission electron microscope in the Nucleus of Microscopy and Microanalysis at Federal University of Viçosa, Brazil.

\section{Results and discussion}

The uterine tube of $H$. mabouia is composed of four distinct regions that are named as follows from the anterior to the posterior side: infundibulum, uterine tube, uterus and vagina (Nogueira et al., 2011a,b). The uterine tube of $H$. mabouia is internally coated with a simple epithelium containing secretory non-ciliated cells and ciliated cells (Fig. 1A and B). Crypts, which are branched epithelial invaginations formed from the epithelial inner lining, are observed inside the uterine tube. The walls of the crypts contain both ciliated and non-ciliated cells; however, very few ciliated cells are present at the bottom. This organization is similar to previous descriptions of crypts in other lizard species (BouResli et al., 1981; Murphy-Walker and Haley, 1996; Girling et al., 1998; Sever and Hamlett, 2002; Yamamoto and Ota, 2006; Eckstut et al., 2009). Sever and Hopkins (2004) and Bou-Resli et al. (1981) described numerous ciliated cells in the neck of the crypts but not at the bottom of Acanthodactylus scutellatus (Gekkonidae) and Scincella laterale uterine tubes. In the uterine tube of Anolis sagrei, the distal portion of the crypt is not specialized; however, the proximal portion exhibits a similar proportion of ciliated and non-ciliated cells (Sever and Hamlett, 2002). Indeed, no apparent pattern regarding the proportion of ciliated and non-ciliated cells is noted among previously studied lizard species.

The non-ciliated cells present in the uterine tube of $H$. mabouia produce a metachromatic secretion when stained with toluidine blue. The secretion produced by non-ciliated epithelial cells located at the bottom of the crypts may be related to a variety of functions, such as nutrition (Cuellar, 1966; Bou-Resli et al., 1981), defense (Bou-Resli et al., 1981), chemotaxis (Saint Girons, 1973; Adams and Cooper, 1988) and maintenance of an aqueous environment, which is appropriate for spermatozoa survival. However, further investigation must be performed to clarify the role of the non-ciliated cell secretions.

Images obtained using scanning electron microscopy (Fig. 2) demonstrate that the bottom of the crypts in the uterine tube of $H$. mabouia exhibit a smooth surface due to the presence of non-ciliated cells. The rough endoplasmic reticulum of the non-ciliated cells is highly developed, and the nucleoli are generally clearly visible and exhibit loose chromatin. Some mitochondria and numerous vesicles dispersed in the cytoplasm can be observed (Figs. 3 and 4). 

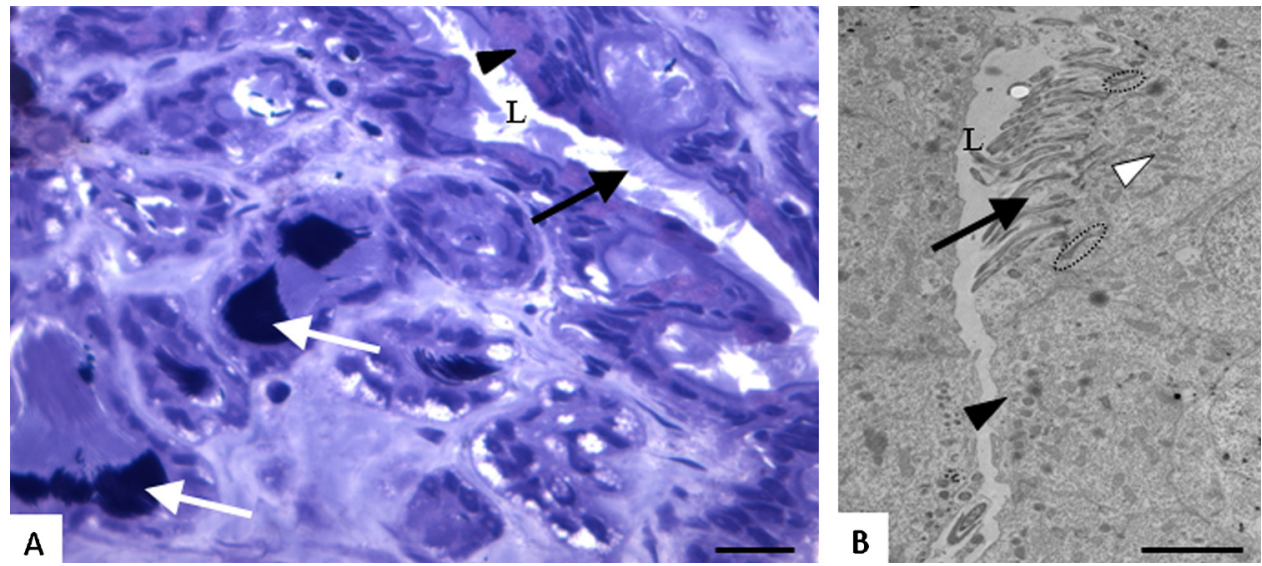

Fig. 1. Light microscopy (A) and transmission electron microscopy (B) of the uterine tube. Note the epithelium composed of ciliated cells (black arrows) and non-ciliated cells (black arrow head). Ciliated cells exhibit elongated basal corpuscles (cycles) on the apical cytoplasm and several mitochondria (white arrow head). Note the presence of clustered spermatozoa (white arrows) at the bottom of the crypts. L, lumen. Bars: A and B, $3 \mu \mathrm{m}$.

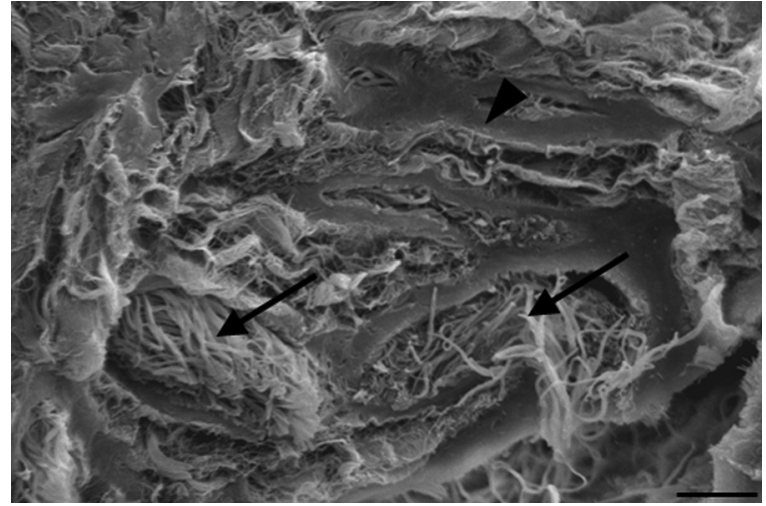

Fig. 2. Scanning electron microscopy of the uterine tube. Note sperm storage (black arrows) and the smooth surface (arrow head) at the bottom of the crypts. Bar. $5 \mu \mathrm{m}$.

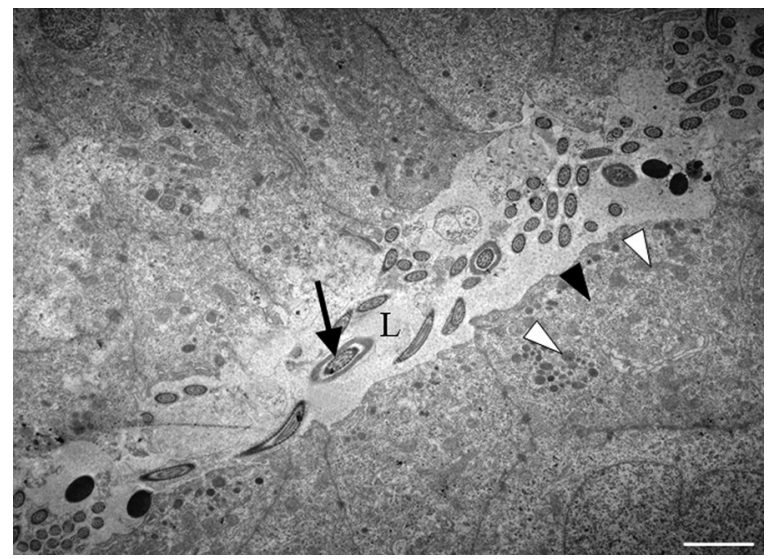

Fig. 3. Transmission electron microscopy of the uterine tube crypt. Note the predominance of the non-ciliated cells. Rough endoplasmic reticulum (black arrow head); mitochondria (white arrows head); spermatozoon (black arrow); L, lumen. Bar: $2 \mu \mathrm{m}$.
Ciliated cells also contain a nucleus with loose chromatin, several mitochondria, elongated basal corpuscles on the apical cytoplasm and moderate amounts of endoplasmic reticulum connected to the nuclear region (Fig. 1).

H. mabouia stores sperm at the bottom of the crypts; the sperm are clustered in bundles with their heads facing towards the blind end of the crypts and tails positioned towards the lumen (Figs. $1 \mathrm{~A}$ and $\mathrm{B}$ and 2). This sperm organization may be related to the chemotactic attraction to substances present within secretions in this region. Moreover, the dense packing of sperm could act as a method to decrease their activity and maintain their viability during storage time. This sperm arrangement during storage was previously observed in other lizard species (Fox, 1963; Conner and Crews, 1980; Sever and Hopkins, 2004; Eckstut et al., 2009) and snakes (Hoffman and Wimsatt, 1972; Halpert et al., 1982; Perkins and Palmer, 1996). The opposite orientation of sperm, with their heads facing the lumen of storage tubules, was observed in Seminatrix pygaea (Siegel and Server, 2007).

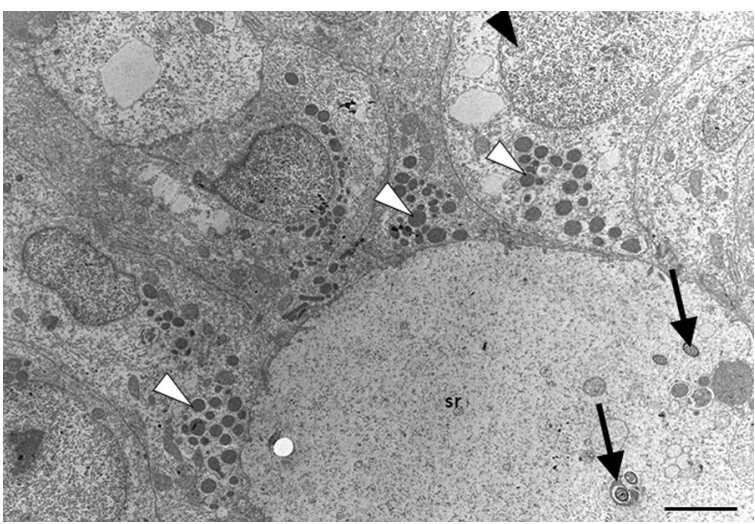

Fig. 4. Transmission electron microscopy of the uterine tube crypt. Note the nucleus with loose chromatin (black arrow head) and numerous vesicles in the cytoplasm of the non-ciliated cells (white arrows head). Note the presence of spermatozoa in transverse sections (arrows) immersed in large amounts of secretion (sr). Bar: $2 \mu \mathrm{m}$. 

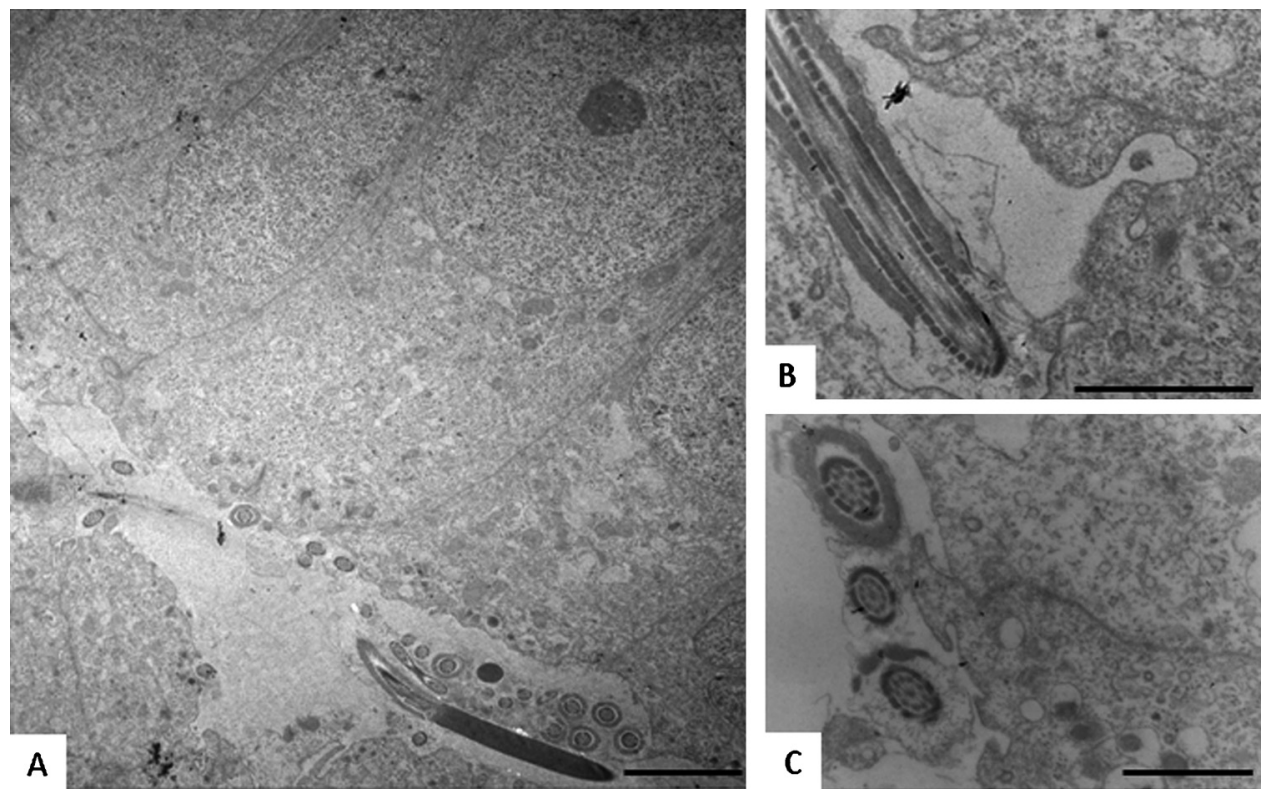

Fig. 5. Transmission electron microscopy of the uterine tube crypt. Note that the spermatozoa do not establish direct contact with epithelial cells. Bars: A, $2 \mu \mathrm{m}$; B and C, $1 \mu \mathrm{m}$.

The sperm stored in the uterine tube crypts of $H$. mabouia does not establish direct contact with epithelial cells (Fig. 5), as observed in Anolis carolinenses (Fox, 1963). However, in other lizards, such as A. scutellatus and E. egregius, sperm was observed in the intercellular spaces and the cytoplasm of epithelial cells (Bou-Resli et al., 1981; Schafer and Roeding, 1973). According to Cuellar (1966) and Adams and Cooper (1988), sperm also appeared to penetrate the epithelial cells in Holbrookia propinqua. This contact between sperm and epithelial cells was also observed in Thamnophis sirtalis, Thamnophis sirtalis parietalis and Agkistrodon piscivorus (Hoffman and Wimsatt, 1972; Halpert et al., 1982; Siegel and Server, 2007). In the garter snake, sperm was observed between the storage tubules, and this interaction was compared to the interaction between sperm and Sertoli cells in mammalian seminiferous tubules (Hoffman and Wimsatt, 1972).

The sperm stored in the uterine tube must reach its lumen for fertilization to occur. The alignment and packing of sperm in $\mathrm{H}$. mabouia do not indicate crypt evacuation as an active process. The sperm release mechanism may be related to the passage of the egg through the uterine tube. Eggs are approximately six millimeters in their largest diameter and exert mechanical pressure against the tube wall, causing its distension and possibly sperm release, as suggested for other species (Fox, 1956; Hoffman and Wimsatt, 1972; Siegel and Server, 2007). The lack of direct contact between the stored sperm and epithelial cells of the crypt ground is a strong evidence to support this hypothesis.

The sperm storage period in $\mathrm{H}$. mabouia was not monitored; however, in the tropical gecko $H$. frenatus, which is phylogenetically close to $H$. mabouia, storage occurs for a minimum period of 36 weeks (Murphy-Walker and Haley, 1996). $H$. frenatus and $H$. mabouia present reproductive cycles that extend throughout the year, which suggests similar storage periods for both species. The possibility of placing litters over the year from egg fertilization by stored sperm decreases predation risks and increases reproductive competition between species that share the same niche. In Florida and Texas, $H$. mabouia, $H$. frenatus and $H$. garnotti exhibit reproductive advantages over their congener $H$. turcicus, which exhibits seasonal reproduction and is being eliminated in those regions (Eckstut et al., 2009).

Based on our observations, we conclude that the crypts of the uterine tube of $\mathrm{H}$. mabouia are the specific site of sperm storage in this species. Furthermore, the morphological organization is similar to other previously studied species of lizards. These findings support the notion that sperm storage is a common reproductive strategy among female reptiles.

\section{Conflict of interest}

None.

\section{Acknowledgments}

We thank the Núcleo de Microscopia e Microanálise of the Universidade Federal de Viçosa and Dr. Gwenaelle Pound-Lana for assistance with English revisions.

\section{References}

Adams, C.S., Cooper, W.E., 1988. Oviductal morphology and spermatozoa storage in the keeled earless lizard, Holbrookia propinqua. Herpetologica 44 (2), 190-197.

Bou-Resli, M.N., Bishay, L.F., Al-Zaid, N.S., 1981. Observations on the one structure of the spermatozoa storage crypts in the lizard Acanthodactylus scutellatus Hardyi. Arch. Biol. (Bruxelles) 92 287-298. 
Carson, F.L., Martin, J.H., Lynn, J.A., 1973. Formalin fixation for electron microscopy: a re-evaluation. Am. J. Clin. Pathol. 59, 365-373.

Conner, J., Crews, D., 1980. Spermatozoa transfer and storage in the lizard, Anolis carolinensis. J. Morphol. 163, 331-348.

Cuellar, O., 1966. Oviductal anatomy and spermatozoa storage structures in lizards. J. Morphol. 119, 7-20.

Eckstut, M.E., Lemons, E.R., Sever, D.M., 2009. Annual dynamics of spermatozoa production and storage in the Mediterranean gecko, Hemidactylus turcicus, in the southeastern United States. Amphibia-Reptilia 30, 45-56.

Fox, W., 1956. Seminal receptacles of snakes. Anat. Rec. 124, 519-540.

Fox, W., 1963. Special tubules for spermatozoa storage in female lizards. Nature 194, 500-501.

Girling, J.E., Cree, A., Guillette Jr., L.J., 1997. Oviductal structure in a viviparous New Zealand gecko, Hoplodactylus maculatus. J. Morphol. 324, 51-68.

Girling, J.E., Cree, A., Guillette Jr., L.J., 1998. Oviductal structure in four species of gekkonid lizard differing in parity mode and eggshell structure. Reprod. Fertil. Dev. 10 (2), 139-154.

Halpert, A.P., Garstka, W.R., Crews, D., 1982. Spermatozoa transport and storage and its relation to the annual sexual cycle of the female red-sided garter snake, Thamnophis sirtalis parietalis. J. Morphol. 174, 149-159.

Hoffman, L.H., Wimsatt, W.A., 1972. Histochemical and electron microscopic observations on the spermatozoa receptacles in the garter snake oviduct. Am. J. Anat. 134, 71-96.

Murphy-Walker, S., Haley, S.R., 1996. Functional spermatozoa storage duration in female Hemidactylus frenatus (Family Gekkonidae). Herpetologica 52 (3), 365-373.

Nogueira, K.O.P.C., Rodrigues, S.S., Araujo, V.A., Neves, C.A., 2011 a. Oviductal structure and ultrastructure of the oviparous gecko, Hemidactylus mabouia (Moreau De Jonne's, 1818). Anat. Rec. (Hoboken, N.J.: 2007) 294, 883-892.
Nogueira, K.O., Araujo, V.A., Rodrigues-Sartori, S.S., Neves, C.A., 2011 b. Phagocytosis of spermatozoa by epithelial cells in the vagina of the lizard Hemidactylus mabouia (Reptilia, Squamata). Micron (Oxford, 1993) 42, 377-380.

Perkins, J.M., Palmer, B.D., 1996. Histology and functional morphology of the oviduct of an oviparous snake, Diadophis punctatus. J. Morphol. 277, 67-79.

Saint Girons, H., 1962. Presence de receptacles seminaux chez les cameleons. Beaufortia 9, 165-172.

Saint Girons, H., 1973. Spermatozoa survival and transport in the female genital tract of reptiles. In: Hafez, E.S.E., Thibault, C.G. (Eds.), The Biology of Spermatozoa. Karger, Basel, Switzerland, pp. 105-113.

Schafer, G.C., Roeding, C.E., 1973. Evidence for vaginal spermatozoa storage in the mole skink, Eumeces egregius. Copeia 1973, 346-347.

Schuett, G.W., 1992. Is long-term spermatozoa storage an important component of the reproductive biology of temperate pitvipers? In: Campbell, J.A., Brodie Jr., E.D. (Eds.), Biology of the Pitvipers. Selva, Tyler, TX, pp. 169-184

Sever, D.M., Hopkins, W.A., 2004. Oviductal spermatozoa storage in the ground skink Scincella laterale Holbrook (Reptilia: Scincidae). J. Exp. Zool. 301A, 599-611.

Sever, D.M., Hamlett, W.C., 2002. Female spermatozoa storage in reptiles. J. Exp. Zool. 292, 187-199.

Sheehan, D.C., Hrapchak, B.B., 1980. Theory and Practice of Histotechnology.

Siegel, D.S., Server, D.M., 2007. Spermatozoa aggregations in female Agkistrodon piscivorus (Reptilia:Squamata): a histological and ultrastructural investigation. J. Morphol. 269 (2), 189-206.

Yamamoto, Y., Ota, H., 2006. Long-term functional sperm storage by a female Common House Gecko, Hemidactylus frenatus, from the Ryukyu Archipelago, Japan. Curr. Herpetol. 25, 39-40. 